\title{
Pharyngeal Stenosis
}

National Cancer Institute

\section{Source}

National Cancer Institute. Pharyngeal Stenosis. NCI Thesaurus. Code C78555.

Narrowing of the pharyngeal airway. 